\title{
Attitudes And Behavior Of Dentists Regarding Management Of Deep Carious Lesion
}

Umeed Javaid, Shama Asghar, Kulsoom Fatima Rizvi

ABSTRACT:

Objective: To assess the attitude and behavior of dentists for the management of deep carious lesions.

Study Design and Setting: It was a cross sectional based study conducted at six dental institutes of Karachi from both government and private sectors.

Methodology: The included participants were the dental graduates and post graduates working in different specialties of dentistry. Whereas graduates and post graduates not affiliated with any institution were excluded from the study. The Questionnaire comprises of two parts, first part was composed of participant's demographic details and academic qualification, while the second part comprised of clinical scenarios regarding management of deep carious lesions.

Results: From the 250 distributed questionnaires, 218 dentists returned the questionnaire giving a satisfactory response rate of $87.2 \%$. There were $28 \%$ male and $72 \% \%$ female dentists. The majority of dentists were aged between $25-35$ years old. Complete caries removal was the management of choice by $72.5 \%$ of dentists for deep carious lesions.

Conclusion: Complete caries removal was the most preferred treatment modality when the risk of dental pulpal exposure associated with caries excavation is low. However when the risk is high, step-wise excavation was preferred procedure by half of the participants.

Keywords: Dental caries, Dental pulp exposure, Dentists, Stepwise excavation.

\section{INTRODUCTION}

A carious lesion is confined destruction of the dental hard tissues caused by acid production of oral bacteria due to fermentation of the dietary carbohydrates ${ }^{1}$. A deep carious lesion occurs when the demineralization extends into middle or inner third of dentin approaching the pulp ${ }^{2}$. Deep carious lesions can be symptomatic or asymptomatic and treating such lesions remains a challenge for dentists. It is very important that pulp status of a tooth must be determined before planning treatment for such lesions ${ }^{3,4}$.

Conventional approach to treat carious lesions is thorough removal of demineralized tissues followed by placement of a well-sealed restoration. ${ }^{5}$ The rationale behind this approach is to remove all the pathological structure leaving sound aseptic dentin before restoration, as improper removal may result in further progression of caries and hence may lead to treatment failures ${ }^{6}$. The most common complication associated with complete caries removal is dental pulpal exposure which requires more complex procedures such as direct pulp capping or root canal treatment ${ }^{7}$. However, with

I Umeed Javaid

Lecturer Operative Dentistry

Bahria University Medical and Dental College

I E-mail: umeedjavaid@hotmail.com

I Shama Asghar

I Associate Professor Operative Dentistry

I Bahria University Medical and Dental College

I Kulsoom Fatima Rizvi

Associate Professor Community Dentistry

Bahria University Medical and Dental College

Received: 07-12-2018

Accepted: 29-04-2019

I Accopted: $2904-2019$ the improvement in technology and materials available nowadays; there have been more conservative strategies introduced in operative field for treating deep carious lesions to avoid pulp exposure such as stepwise or selective removal of caries $^{5,8}$.

Step-wise excavation involves two steps, in first step incomplete excavation is done leaving some carious dentin avoiding pulpal exposure, followed by sealing of residual dentin with the medicating material ${ }^{9}$. It is done to initiate remineralization through formation of tertiary dentin over the pulp. In the second step, once a tertiary dentin forms, operator re-enters the cavity after few months to remove residual dentin without endangering the pulp followed by restoration ${ }^{2,9}$. Whereas in selective removal or one step removal, some carious dentin is left behind omitting the step of re-entry in the cavity ${ }^{5}$. The mechanism of stepwise or selective removal is that remaining bacteria are deprived from its nutrition hence the bacterial activity will be inert and the vital pulp is safe ${ }^{10}$. Multiple studies ${ }^{11,12,13}$ reported that these conservative procedures are better than a conventional approach in maintaining the vitality and integrity of a dental pulp.

Most of the dental schools in the world still recommended complete elimination of bacteria in soft dentin ignoring newest conservative approaches. Studies conducted in various parts of the world like Saudia Arabia ${ }^{14}$, Palestine ${ }^{2}$ and France ${ }^{15}$ showed that majority of their dentists followed conventional approach. However, study conducted among Norwegian dentists $^{13}$ found that most of them follow conservative approach. To the best of our knowledge there is no such study conducted at the national level regarding approaches 
employed by our dentists in cases of deep carious lesions and indeed it was the rationale of this study. Therefore the aim of the study was to assess the attitudes and behavior regarding the preferred method to manage the deep carious lesion with relation to qualification and clinical standing of different dentists in Karachi.

\section{METHODOLOGY:}

A cross-sectional, multi-centered study was conducted in six government and private dental institutes of Karachi from April to June 2018. Taking previous study as a reference ${ }^{16}$ for sample size, keeping margin of error $5 \%$ and $95 \%$ confidence interval, the calculated sample size was 218 participants according to OpenEpi (Version 3). The expected dropout was $13 \%$ dropouts hence total 250 participants were required to obtain the desired outcome. The included participants were dental graduates and post graduates belonging to clinical and non-clinical of public and private sector. Whereas graduates and post graduates not affiliated with any institution were excluded from the study. A selfadministered questionnaire was distributed among the subjects through convenience sample technique and they were asked for written consent before filling the forms. Ethical approval was obtained from Ethical Review Committee of Bahria University Medical and Dental College numbered (ERC 11/2018).

The questionnaire was a modified version of a previously used study of Falk Schwendicke et al and Taleb Hussain Alnahwiet al. ${ }^{16,17}$ The questionnaire was divided into two parts; first part was regarding demographic details and academic qualification (BDS level-I, MCPS/MSc level-II, FCPS/MDS level III) and in the second part cases regarding management of deep carious lesions were asked.

The questionnaire assessed the knowledge and behavior of dentists regarding management of deep caries in the following areas:(1) criteria to assess carious tissue removal in deep lesions, (2) methods for carious tissue removal, (3) procedures/techniques used to improve prognosis of procedure (4) management strategies for a deep lesion. (5) Attitudes towards leaving carious tissue beneath a restoration and (6) reasons of underlying the treatment decisions.

A statistical analysis was performed in SPSS Version 22.0. Descriptive analysis was carried out for qualitative variables, and means and standard deviations were determined for quantitative variables. Chi-square test was used to compare study responses between qualification and clinical standing at a significance level of $=0.05$.

\section{RESULTS:}

Out of the 250 dentists, 218 returned the questionnaire giving a satisfactory response rate of $(87.2 \%)$. Respondents include $(28 \%)$ male and $(72 \%)$ female dentists and the majority of them aged between 25-35 years old. (Figure 1)Most of the participants were graduates (Level 1) $(84.9 \%)$ followed by post graduates (15.1\%) (Level II and III).

Hardness of the dentine was the criteria most often used for assessing the carious tissue removal. Majority of respondents (73.3\%) preferred removing the soft dentine. Almost (56.9\%) considered wet dentin as main criteria while removing deep carious lesion. Color of the lesion was not significant for most of the respondents and was selected by (47.7\%) only. When inquired about the preferred excavation method, majority preferred metal bur (slow and high) (56\%) followed by hand excavation $(41.7 \%)$ and few respondents selected chemo mechanical $(2.3 \%)$ methods. The most selected method of cavity disinfection to improve prognosis was rubber dam (60.6\%).Complete caries removal was chosen by $(72.5 \%)$ dentists when there was no risk of pulp involvement. Whereas $(48.6 \%)$ agreed on removing complete caries where risk of pulp exposure is involved and (47.7\%) disagreed to it. (84.9\%) participants selected that their interventions are based on evidences whereas only (6.4\%) participants selected recommendations by peers. (Table 1)

When graduate and post graduates were compared regarding management of deep carious lesions we found no difference among them. $(p$ value $=.05)($ Table 1$)$

\section{DISCUSSION:}

This study was done to assess attitudes and behavior regarding the preferred method to manage the deep carious lesion with relation to qualification and clinical standing of different dentists in Karachi. Deep carious lesions can cause pulp exposure in where complete caries is removed, in such cases dentists relies on minimal invasive procedures such as pulp capping, pulpotomy or pulpectomy ${ }^{18,19}$. In our study (72.5\%) of dentists preferred complete caries removal when there was no risk of pulp exposure which was comparable to (71.1\%) of Southern Brazil ${ }^{2}$ and lower than Saudi Arabia ${ }^{16}$ which was $(82.5 \%)$. According to our study $(47.7 \%)$ of dentists were preferred step-wise excavation when pulp is in close proximity and these results were higher than $17.6 \%$ in Brazil ${ }^{2}$ and lower (57.8\%) than the findings of Saudi Arabia ${ }^{16}$ and in France ${ }^{17}$ which was (71\%). Studies have shown that risk of pulp exposure was considerably reduced in selective carious removal technique in contrast to nonselective carious removal ${ }^{20,21,22}$.

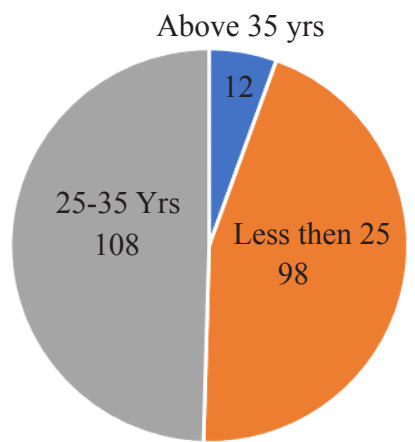

Fig- I Age distribution of the participants of the study 
Attitudes And Behavior Of Dentists Regarding Management Of Deep Carious Lesion

Table 1. Cross tabulation between Attitudes and behavior of dentists regarding deep carious lesion management among different qualifications.

\begin{tabular}{|c|c|c|c|c|c|c|}
\hline Question & Criteria /method & BDS n(\%) & MCPS/MSc n(\%) & FCPS/MDS n(\%) & Total n(\%) & p-value \\
\hline \multirow{3}{*}{ Hardness of dentin } & Soft & $136(73.5)$ & $12(75)$ & $12(70.5)$ & $160(73.3)$ & \multirow{3}{*}{0.884} \\
\hline & Leathery & $38(20.5)$ & $4(25)$ & $4(25)$ & $46(21.1)$ & \\
\hline & Not Relevant & $11(6)$ & $0(0)$ & $1(23.5)$ & $12(5.5)$ & \\
\hline \multirow{3}{*}{ Color of the lesion } & Heavily stained & $88(47.5)$ & $8(50)$ & $8(47)$ & $104(47.7)$ & \multirow{3}{*}{0.999} \\
\hline & Normal to yellow & $62(33.5)$ & $5(31.25)$ & $6(35.2)$ & $73(33.4)$ & \\
\hline & Not Relevant & $35(18.9)$ & $3(18.7)$ & $3(17.6)$ & $41(18.8)$ & \\
\hline \multirow{3}{*}{$\begin{array}{l}\text { Moisture content of } \\
\text { the lesion }\end{array}$} & Wet & $99(53.5)$ & $11(68.7)$ & $14(82.3)$ & $124(56.8)$ & \multirow{3}{*}{0.123} \\
\hline & Dry & $47(25.4)$ & $4(25)$ & $2(11.7)$ & 5324.3) & \\
\hline & Not Relevant & $39(21)$ & $1(6.25)$ & $1(5.88)$ & $41(18.8)$ & \\
\hline \multirow{3}{*}{$\begin{array}{l}\text { Excavation } \\
\text { methods }\end{array}$} & Metal bur (high and slow speed) & $109(58.9)$ & $7(43.75)$ & $6(35.29)$ & $122(55.9)$ & \multirow{3}{*}{0.223} \\
\hline & Hand excavation & $72(38.9)$ & $9(56.25)$ & $10(58.8)$ & $91(41.7)$ & \\
\hline & Chemo-mechanical & $4(2.16)$ & $0(0)$ & $1(5.88)$ & $5(2.29)$ & \\
\hline \multirow{3}{*}{$\begin{array}{l}\text { Additional } \\
\text { procedures/techni } \\
\text { ques }\end{array}$} & Rubber dam & $112(60.5)$ & $10(62.5)$ & $10(58.8)$ & $132(60.5)$ & \multirow{3}{*}{0.990} \\
\hline & Cavity disinfection & $55(29.7)$ & $4(25)$ & $5(29.4)$ & $64(29.3)$ & \\
\hline & Others & $18(9.72)$ & $2(12.5)$ & $2(11.7)$ & $22(10.0)$ & \\
\hline \multirow{3}{*}{$\begin{array}{l}\text { Complete } \\
\text { excavation }\end{array}$} & Agree & $139(75.1)$ & $11(68.7)$ & $8(47.0)$ & $158(72.4)$ & \multirow{3}{*}{0.055} \\
\hline & Disagree & $40(21.6)$ & $5(31.25)$ & $9(52.9)$ & $54(24.7)$ & \\
\hline & No opinion & $6(3.24)$ & $0(0)$ & $0(0)$ & $6(2.75)$ & \\
\hline \multirow{3}{*}{$\begin{array}{l}\text { Incomplete } \\
\text { excavation }\end{array}$} & Agree & $82(44.3)$ & $9(56.2)$ & $13(76.4)$ & $104(47.7)$ & \multirow{3}{*}{0.106} \\
\hline & Disagree & $95(51.35)$ & $7(43.75)$ & $4(23.5)$ & $106(48.6)$ & \\
\hline & No opinion & $8(4.32)$ & $0(0)$ & $0(0)$ & $8(3.66)$ & \\
\hline \multirow{4}{*}{$\begin{array}{l}\text { Deep caries } \\
\text { management }\end{array}$} & Evidence based & $156(84.3)$ & $13(81.2)$ & $16(94.1)$ & $185(84.8)$ & \multirow{3}{*}{0.639} \\
\hline & Recommended by peers & $12(6.48)$ & $2(12.5)$ & $0(0)$ & $14(6.42)$ & \\
\hline & Cost effective & $17(9.18)$ & $1(6.25)$ & $1(5.88)$ & $19(8.71)$ & \\
\hline & Total $\mathbf{n}$ & 185 & 16 & 17 & 218 & \\
\hline
\end{tabular}

No statistically significant differences were found between simple graduates and post graduates respondents regarding the management of deep caries, $(P>0.05)$.

This study showed the higher preference for complete caries removal possibly due to unawareness about the advantages of minimal invasive techniques ${ }^{23}$. The results clearly indicated that involvement of pulp alters the decision of treatment. Different studies ${ }^{20,23}$ showed that even if practitioners are aware of newer techniques, such as minimally invasive dentistry (MID) they are not completely following it and still prefers practicing an old methodology which is the removal of all the infected tissue. ${ }^{20,23,24}$

Our study revealed that hardness as the most chosen criteria to evaluate the extent of deep carious lesion which is in agreement to the studies done previously in Palestine ${ }^{22}$, France $^{17}$, Germany ${ }^{12}$ and Norway ${ }^{15}$. Hardness has been set as marker to evaluate the lesion's extent as no reliable diagnostic tool has been validated. However, it should be highlighted and considered that inactive slow progressing carious lesion can progress anytime. ${ }^{25}$

Dentine hardness is found to be the criterion endorsed by the International Caries Consensus Collaboration (ICCC) group in order to establish the clinical consequences of the disease ${ }^{11}$.In our study no association between gender and levels of qualification was found on treatment decision. However, previous studies show that younger dentists tend to select more conservative approaches ${ }^{2,15}$. In addition some literature revealed that experienced dentists conduct their treatment based on latest evidences for deep carious lesions. ${ }^{15,26,27}$ In terms of limitations of this study these results were from the Institutes of Karachi only, hence results were unable to generalize to all dentists of the country. Another limitation was reporting bias as participants may answer what they actually did not practice. It is recommended that minimally invasive approaches for caries management should be added to the dental curriculum. Workshops should also be conducted to update practicing dentists to eradicate the fear of leaving affected dentin.

\section{CONCLUSION}

The results of this study revealed that complete caries removal was the treatment of choice when there was no 
chance of pulp exposure and step-wise excavation was done by half of the participants when there was chance of pulp exposure. The result also highlights a contrasting response from the participants as they believe in evidence based dentistry but do not apply those concepts in their daily practice.

\section{REFRENCES:}

1. Fontana M, Young DA, Wolff MS, Pitts NB, Longbottom C. Defining dental caries for 2010 and beyond. Dent ClinNorth Ame. 2010;54(3):423-40.

2. Weber CM, Alves LS, Maltz M. Treatment decisions for deep carious lesions in the Public Health Service in Southern Brazil. J Public Health Dent. 2011;71(4):265-70.

3. Phonghanyudh A, Phantumvanit P, Songpaisan Y, Petersen PE. Clinical evaluation of three caries removal approaches in primary teeth: a randomized controlled trial. Comm Dent Health. 2012;29(2):173-8

4. Pigg M, Nixdorf DR, Nguyen RH, Law AS, National Dental Practice-Based Research Network Collaborative Group. Validity of preoperative clinical findings to identify dental pulp status: A national dental practice-based research network study. Journal of Endodontics. 2016;42:935-42.

5. Schwendicke F, Schweigel H, Petrou MA, Santamaria R, Hopfenmüller W, Finke C, Paris S. Selective or stepwise removal of deep caries in deciduous molars: study protocol for a randomized controlled trial. Trials. 2015;16(1):11.

6. Banerjee A, Frencken JE, Schwendicke F, Innes NPT. Contemporary operative caries management: consensus recommendations on minimally invasive caries removal. British Dental Journal. 2017;223:215-22.

7. Wenzel A. Radiographic display of carious lesions and cavitation in approximal surfaces: Advantages and drawbacks of conventional and advanced modalities. Acta Odontologica Scandinavica. 2014;72:251-64

8. Koopaeei MM, Inglehart MR, McDonald N, Fontana M. General dentists', pediatric dentists', and endodontists' diagnostic assessment and treatment strategies for deep carious lesions. A comparative analysis. Journal of the American Dental Association. 2017;148:64-74.

9. Maltz M, Garcia R, Jardim JJ, De Paula LM, Yamaguti PM, Moura MS, Garcia F, Nascimento C, Oliveira A, Mestrinho HD. Randomized trial of partial vs. stepwise caries removal: 3-year follow-up. J Dental Res. 2012;91(11):1026-31.

10. Herrera Martínez H, Bonilla Represa V, Segura Egea JJ. Caries disease versus caries lesion: diagnostic and therapeutic implications according to the International Caries Consensus Collaboration Group. Endodoncia. 2016;34:204-19

11. Crespo-Gallardo I, Hay-Levytska O, Martín-González J, Jiménez-Sánchez MC, Sánchez-Domínguez B, Segura-Egea JJ. Criteria and treatment decisions in the management of deep caries lesions: Is there endodontic overtreatment? J ClinExp Dent. 2018;10(8):e751-60

12. Schwendicke F, Meyer-Lueckel H, Dörfer C, Paris S. Attitudes and behaviour regarding deep dentin caries removal: a survey among German dentists. Caries Res. 2013;47(6):566-73.
13. Stangvaltaite L, Kundzina R, Bolstad NL, Eriksen HM, Kerosuo E. Deep carious lesions and other consequences of caries among 18-year-olds at Public Dental Health Service in Northern Norway: A cross-sectional age cohort study. ActaOdontol Scand. 2015;73(6):401-7.

14. Siddqui AA, Alharbi TM, Rashidi FF. Deep carious lesions: respondent perception, knowledge and attitude of its management. Ind Am J Pharm Sci. 2018 Dec 1;5(12):1697885.

15. Schwendicke F, Göstemeyer G. Understanding dentists' management of deep carious lesions in permanent teeth: a systematic review and meta-analysis. Implement Sci. 2016 ;11(1):142.

16. Alnahwi TH, Alhamad M, Majeed A, Nazir MA. Management preferences of deep caries in permanent teeth among dentists in Saudi Arabia. Eur J Dent. 2018;12(2):300-4

17. Schwendicke F, Stangvaltaite L, Holmgren C, et al. Dentists' attitudes and behaviour regarding deep carious lesion management: a multi-national survey. Clin Oral Investig. 2017;21(1):191-8.

18. Mattos J, Soares GM, Ribeiro AD. Current status of conservative treatment of deep carious lesions. Dent update. 2014;41(5):452-6.

19. Unlu N, Ermis RB, Sener S, Kucukyilmaz E, Cetin AR. An in vitro comparison of different diagnostic methods in detection of residual dentinal caries. Int J Dent. 2010;864935:1-8.

20. Li T, Zhai X, Song F, Zhu H. Selective versus non-selective removal for dental caries: a systematic review and metaanalysis. ActaOdontol Scand. 2018;76(2):135-40.

21. Schwendicke F, Frencken J, Innes N. Current Concepts in Carious Tissue Removal. Curr Oral Health. 2018;5(3):15462.

22. Rabi T. Knowledge, Attitude, and Practice Survey of Dentists in Palestine toward Deep Dentin Caries Removal. Cons Dent Endod J 2016 July 1(2):28-32.

23. Katz CR, de Andrade MD, Lira SS, Ramos Vieira EL, Heimer MV. The concepts of minimally invasive dentistry and its impact on clinical practice: a survey with a group of Brazilian professionals. Int J Dent. 2013 Apr;63(2):85-90.

24. Santamaria R, Innes N. Trial shows partial caries removal is an effective technique in primary molars.Evid Based Dent 2014;15(3):81-2.

25. Lehmann M, Veitz-Keenan A, Matthews AG, Vena D, Grill A, Craig RG, Curro FA, Thompson VP. Dentin caries activity in early occlusal lesions selected to receive operative treatment: findings from the Practitioners Engaged in Applied Research and Learning (PEARL) Network. J Am Dent Assoc. 2012;143(4):377-85.

26. Vural U. Treatment method and restorative material preferences of dental practitioners. Eur J Gen Dent. 2016;5(1):19-23.

27. Segura-Egea JJ. Complete excavation or removal of carious tissues to hard dentin: Overtreatment. J Oral Res. 2017;6(2):301. 